\title{
Casos alóctones de leishmaniose visceral canina no Paraná, Brasil: implicaçóes epidemiológicas
}

\author{
Allochthonous cases of canine visceral leishmaniasis in Paraná, Brazil: epidemiological implications \\ Vanete Thomaz-Soccol ${ }^{1 *}$; Edilene A. Castro ${ }^{1}$; Italmar Teodorico Navarro²; Marconi Rodrigues de Farias ${ }^{3}$; \\ Lília Maria de Souza ${ }^{4}$; Yanê Carvalho'; Saloé Bispo ${ }^{1}$; Norberto Assis Membrive \\ Joáo Carlos Minozzo ${ }^{1}$; Jessé Truppel ${ }^{1}$; Wagner Bueno ${ }^{4}$; Ennio Luz ${ }^{1}$
}

${ }^{1}$ Laboratório de Parasitologia Molecular, Setor de Ciências Biológicas, Centro Politécnico, Universidade Federal do Paraná - UFPR

${ }^{2}$ Departamento de Medicina Veterinária Preventiva, Centro de Ciências Agrárias, Universidade Estadual de Londrina - UEL

${ }^{3}$ Clínica Veterinária, Curso de Medicina Veterinária, Pontifícia Universidade Católica do Paraná - PUC

${ }^{4}$ Médicos Veterinários Autônomos de Curitiba - PR

${ }^{5}$ Laboratório de Vigilância Epidemiológica

Recebido em 20 de Novembro de 2008

Aceito em 23 de Janeiro de 2009

\section{Resumo}

O presente trabalho teve como objetivo pesquisar a ocorrência de leishmaniose visceral em cães com sinais clínicos compatíveis, procedentes de clínicas veterinárias das diferentes regiôes do Estado do Paraná e em caso positivo verificar a autoctonia dos mesmos. Dos animais com suspeita clínica e epidemiológica de LV, foi coletada amostra de sangue para realização de hemograma, provas bioquímicas, sorologia, cultura do parasito, PCR e RAPD. Os cães portadores de quadro clínico, como febre, hiperqueratose, onicogrifose e emagrecimento exagerado, tiveram gânglio poplíteo e/ou medula óssea puncionados e o conteúdo inoculado em meio de cultivo NNN. A extração de DNA do parasito em sangue e cultura foi realizada pelo método fenol/clorofórmio. A amplificação de DNA do protozoário foi feita por PCR e RAPD. Dos 24 animais analisados, o parasito foi isolado em 19 cães. As técnicas moleculares permitiram identificar 14 isolados como L. (Leihmania) infantum e cinco como L. (Viannia) braziliensis. A análise epidemiológica dos casos permitiu determinar o local de transmissão e definir que todos os cáes com LV diagnosticados eram casos alóctones, ou seja eram importados de regiốes endêmicas. Sugere-se que a migraçáo dos cáes de regióes endêmicas para regióes indenes poderá permitir a instalação de novos focos, desde que o agente encontre ecótopo adequado e vetor específico (Lutzomyia longipalpis).

Palavras-chave: Leishmaniose visceral, Leishmania infantum, cães, casos alóctones, epidemiologia.

\begin{abstract}
The south region is the only area in Brazil that does not present autochthonous cases of visceral leishmaniasis $(\mathrm{VL})$, however, in the state of Parana, dogs and humans have been found showing a VL compatible clinical profile. In view of this problem, the present work aimed at isolating and identifying the parasite and determining the cases autochthony. All animals clinically suspect of VL were clinically evaluated, and had samples of their blood collected for hemoculture (NNN culture medium), serology, PCR and RAPD-PCR, hemogram, and biochemical assays. The dogs presenting VL clinical profile had their lymph nodes and/or bone marrow punctured and their content inoculated in NNN culture medium. The protozoan isolated was identified by PCR and PCR-RAPD. Strains of Leishmania were isolated in 19 out of the 24 studied animals. Fourteen isolates were identified as L. (Leishmania) infantum, and five were L. (Viannia) braziliensis. In the epidemiological analysis, it was possible to determine that all dogs with $L$. $(L$.) infantum being allochthonous cases. Leishmaniasis is a zoonose that has the domestic dog as reservoir, the migration of such animals can disseminate the parasite to other regions, provided the agent finds an adequate ecotope and a specific vector (Lutzomyia longipalpis).
\end{abstract}

Keywords: Visceral leishmaniasis, Leishmania infantum, dogs, allochthonous cases, epidemiology.

\footnotetext{
*Autor para correspondência: Vanete Thomaz-Soccol

Laboratório Parasitologia Molecular, Setor de Ciências Biológicas, Centro Politécnico,

Universidade Federal do Paraná - UFPR, Rua Cel. Francisco H. dos Santos, s/n,

Jardim das Américas, CEP 81531-990 Curitiba - PR, Brasil; e-mail: vasoccol@ufpr.br
} 


\section{Introdução}

A leishmaniose visceral (LV) é uma importante zoonose com ampla distribuição geográfica, incluindo Oriente Médio, África e Américas Central e do Sul. No continente americano, a doença recebe a denominação de leishmaniose visceral americana (LVA) e é causada por L. infantum sin. L. chagasi (MORENO et al., 1986; THOMAZ-SOCCOL, 1993). É um protozoário viscerotrópico presente na forma amastigota, em células do sistema fagocitário mononuclear dos hospedeiros vertebrados, cães e homem (LAINSON; SHAW, 1987). Nos hospedeiros invertebrados, Lutzomyia longipalpis, o parasito se encontra na forma promastigota no intestino.

A doença é considerada uma das seis doenças mais importantes causadas por protozoários no mundo (WHO, 2001). No cáo, as manifestações clínicas estão associadas, inicialmente, ao tipo de resposta imunológica desenvolvida. Os animais infectados podem apresentar-se assintomáticos, oligossintomáticos e sintomáticos (BRASIL, 2004; GONTIJO; MELO, 2004). Os sinais clínicos mais comumente observados nos cáes são: linfoadenomegalia, onicogrifose, emaciaçáo, queda de pelos, lesôes ulcerativas, prurido, pelos opacos, diarreia, ceratoconjutivite, esplenomegalia, hemorragia intestinal, edema de patas, hiperqueratose, dentre outros. Em estágios mais avançados, observa-se também paresia das patas posteriores, caquexia, inaniçáo, evoluindo para a morte (FEITOSA et al., 2000; BRASIL, 2004; ALBUQUERQUE et al., 2007).

A partir da suspeita clínica, a confirmação do diagnóstico da LV é feita por exames parasitológicos, imunológicos e moleculares. Os métodos parasitológicos representam o padrão ouro, e os métodos sorológicos são os mais utilizados em inquéritos (WHO, 2001; BRASIL, 2004). Todos os métodos de diagnóstico e de identificaçâo de Leishmania apresentam vantagens e desvantagens. Mas, para confirmar a autoctonia de casos, os métodos parasitológicos são indispensáveis e atendem ao postulado de Koch (1882), ou seja, antes de estabelecer e aceitar uma relação causal entre um dado agente etiológico e a doença em questâo, é necessário o isolamento e a correta identificação do parasito.

A especificidade do método parasitológico é de $100 \%$ e a sensibilidade pode ultrapassar $80 \%$ quando o material colhido é punção do gânglio poplíteo ou camada leucocitária (BONI; DAVOUST; DEREURE, 1999). No entanto, essa metodologia náo permite a identificação da espécie. Técnica de eletroforese de isoenzima é sugerida como técnica padrão pela OMS (WHO, 1990; THOMAZ-SOCCOL et al., 1993). No entanto, técnicas moleculares como RAPD-PCR ou PCR vêm sendo empregadas para a identificação de espécie (PEREIRA, 2005; PEREIRA et al., 2008). Na técnica de PCR, o emprego de um único par de iniciadores específicos permite identificar somente a espécie em questấo. A vantagem de técnicas como o RAPD-PCR é que isolados desconhecidos podem ser comparados com várias amostras referências segundo seu perfil eletroforético, o que permitirá, por comparação, chegar ao agente etiológico.

A leishmaniose visceral tem aumentado significativamente no Brasil com total de 60.969 casos, entre 1980 a 2005, somente em humanos. Nos anos 90, o número médio de casos anuais era de 1.500 e, a partir de 2001, passaram a ser registrados em torno de
3.000 casos. Em 2000, o número oficial foi de 4.858 casos em humanos (BRASIL, 2008).

Os aspectos epidemiológicos da LV, no Brasil, vêm sofrendo alteraçôes. Inicialmente, como no Nordeste brasileiro, a incidência da doença era associada à pobreza, subnutrição humana e canina e áreas rurais e/ou silvestres. Atualmente, no Sudeste e Centro-oeste, a doença está ocorrendo em regióes urbanas ou periurbanas, mostrando assim a urbanizaçáo da LV (SILVA et al., 2001; GONTIJO; MELO, 2004; BORASCHI; NUNES, 2007). Na Região Sul, não ocorrem casos autóctones de LV por náo ser observado vetor espécie específico. Porém, cáes e humanos com sinais clínicos compatíveis com LV vêm sendo observados no Estado do Paraná. O presente trabalho teve como objetivo avaliar a ocorrência de leishmaniose visceral em cães com alteraçôes clínicas, procedentes de diferentes regiōes do Estado do Paraná e verificar a autoctonia dos mesmos.

\section{Material e Métodos}

\section{Diagnóstico clínico}

Os animais com suspeita clínica de leishmaniose visceral foram avaliados clinicamente, adotando-se a classificaçáo de Abranches et al. (1991), modificada por Molina et al. (1994).

\section{Exames complementares}

Dos animais submetidos ao exame clínico, foram colhidos $5 \mathrm{~mL}$ de sangue, sendo $2 \mathrm{~mL}$ com anticoagulante (EDTA) para realização de hemocultura, (DEREURE et al., 1998), reação em Cadeia da Polimerase - PCR (LACHAUD et al., 2002) e hemograma (GARCIA-NAVARRO; PACHALY, 1994); e os outros $3 \mathrm{~mL}$ foram colhidos sem anticoagulante para separaçáo do soro e pesquisa de anticorpos (reação de imunofluorescência indireta - RIFI e ensaio imunoenzemático - ELISA); avaliação das funçôes hepática e renal pelas dosagens ALT - PP (ANALISA) e método cinético UV; FA - ACP - 405 (WEINER LAB.) método cinético otimizado - $405 \mathrm{~nm}$; creatinina K (LAB TEST) método cinético otimizado e Uréia CE (LAB TEST) método enzimático colorimético. Todos os métodos foram realizados segundo recomendaçôes dos fabricantes.

\section{Sorologia}

A determinação dos títulos dos anticorpos ( $\operatorname{IgG}$ ) contra Leishmania foi realizada pelas técnicas de RIFI, empregando-se conjugado anti-IgG de cão (isotiocianato de fluoresceína - Sigma) e o ELISA, utilizando-se conjugado anti-IgG de cão (peroxidase - Sigma), padronizados conforme Castro, Thomaz-Soccol e Augur (2003). Títulos iguais ou superiores a 1:40 foram considerados positivos para a RIFI, e o ponto de corte para a reaçáo de ELISA foi considerado de 0,135 , valor este que representa a média dos valores de absorbância dos animais negativos (nascidos em Curitiba) mais dois desvios- padrão, repetidos em cada placa. 


\section{Isolamento e cultivo do parasito}

Foi realizada a biópsia aspirativa do gânglio poplíteo, ou biópsia de pele. $\mathrm{O}$ aspirado de gânglio foi inoculado diretamente em meio de cultivo NNN, contendo $0,5 \mathrm{~mL}$ de soro fisiológico com penicilina $(25.000 \mathrm{UI})+$ estreptomicina $\left(100 \mu \mathrm{g} \cdot \mathrm{mL}^{-1}\right)$ para isolamento. Os fragmentos da biópsia passavam por antissepcia, maceração, adição de $0,5 \mathrm{~mL}$ de sorofisiológico contendo antibiótico. Os isolados foram catalogadas sob a sigla CUR (CURITIBA), seguida de numeração correspondente à ordem de entrada, segundo recomendaçóes propostas pelo "Colloque International de Montpellier”, França (RIOUX, 1986).

Para a obtenção de grande quantidade de promastigotas, visando à extração do DNA para as etapas de PCR e RAPD-PCR, os protozoários foram inoculados em meio RPMI, suplementados com $10 \%$ de soro fetal bovino, em garrafa de cultivo celular de $100 \mathrm{~mL}$, por 7 dias, em estufa a $24^{\circ} \mathrm{C}$. Após crescimento, o sedimento foi recuperado, lavado com tampão Tris-HCL $\mathrm{pH} 8.0$, centrifugado a $10.000 \times \mathrm{g}$ por 5 minutos e o sedimento armazenado a $-20{ }^{\circ} \mathrm{C}$.

\section{Reação em Cadeia da Polimerase (PCR) e Polimorfismo de DNA Amplificado ao Acaso (RAPD - PCR)}

As extraçôes de DNA foram realizadas em tubos plásticos de 2,0 mL, que continham no sedimento formas promastigotas de Leishmania. Foram adicionados $400 \mu \mathrm{L}$ de tampáo de lise (TE), $\mathrm{pH}$ $=8,0,50 \mu \mathrm{L}$ SDS a $10 \%$ e $5 \mu \mathrm{L}$ de Proteinase $\mathrm{K}\left(20 \mathrm{mg} \cdot \mathrm{mL}^{-1}\right)$, em banho-maria, por 2 horas, a $56^{\circ} \mathrm{C}$. Posteriormente, desnaturou-se a proteinase $\mathrm{K}$, aquecendo-se os tubos a $95^{\circ} \mathrm{C}$ por 10 minutos. Em seguida, foram adicionados $5 \mu \mathrm{L}$ de RNAse $\left(20 \mathrm{mg} \cdot \mathrm{mL}^{-1}\right)$, homogeneizados e incubados em banho-maria, a $37^{\circ} \mathrm{C}$, por 2 horas. Adicionou-se fenol saturado (fase inferior) volume/volume e, após a centrifugação, $10000 \mathrm{~g}$ por 5 minutos a $20^{\circ} \mathrm{C}$, recuperou-se o sobrenadante e fez-se uma segunda extração com fenol. Após esse procedimento, foi adicionado fenol clorofórmio (volume/volume) e nova centrifugação $\left(10000 \mathrm{~g}, 5\right.$ minutos, a $20^{\circ} \mathrm{C}$ ). Esse procedimento foi repetido duas vezes, sendo recuperada a fase superior e submetida a extração com clorofórmio. O DNA do sobrenadante foi precipitado com acetado de sódio a $3 \mathrm{M}$ e 2 volumes de etanol $96 \%$ a $4{ }^{\circ} \mathrm{C}$. Após incubação por 18 horas a $-20{ }^{\circ} \mathrm{C}$ foi realizada centrifugação a $10000 \mathrm{~g}$, por 30 minutos a $4^{\circ} \mathrm{C}$. O sobrenadante foi desprezado e o precipitado lavado duas vezes com $300 \mu \mathrm{L}$ de etanol $70^{\circ}$. O precipitado foi deixado para secar, por 10 minutos, em estufa a $37^{\circ} \mathrm{C}$ e, após esse tempo, foi hidratado com $100 \mu \mathrm{L}$ de água ultrapura e mantido a $-80^{\circ} \mathrm{C}$ até seu uso.

As quantificaçóes de DNA, tanto das amostras referências como das amostras isoladas no presente trabalho, foram feitas pela medida de absorbância a $260 \mathrm{~nm}$ em espectrofotômetro (Gene Quant ${ }^{\oplus}$ ).

Para identificar o complexo L.(L.) infantum por PCR, foram usados os iniciadores RV1/RV2 desenhados com base no DNA alvo altamente repetitivo do minicírculo do kDNA de Leishmania donovani sensu lato, segundo metodologia descrita por Lachaud et al. (2002).
A técnica de RAPD-PCR foi realizada para os isolados com resultado de PCR negativos. Foram usados quatro oligonucleotídeos iniciadores (A2 - TGCCGAGCTG; A3 - AGTCAGCCAC; A9 - GGGTAACGCC e A10 - GTGATCGCAG) (BAÑULS, 1998). As condições de amplificação foram realizadas segundo protocolo proposto por Pereira (2005). Em resumo: as reaçóes foram realizadas para $25 \mu \mathrm{L}$ com $10 \mathrm{mM}$ Tris-Cl, pH 8,3, $50 \mathrm{mM} \mathrm{KCl}$, 1,5 mM MgCl$, 0,2 \mathrm{mM} \mathrm{dNTP} \mathrm{(deoxinucleotide} \mathrm{triphosphate),}$ 10 pmol de oligonucleotídeo iniciador, DNA diluído 1:40 e 2,5 U de Taq DNA polymerase (Invitrogen). A amplificação consistiu em um ciclo inicial de desnaturaçáo a $94^{\circ} \mathrm{C}$ por 5 minutos, 40 ciclos de desnaturação a $94^{\circ} \mathrm{C}$ por 1 minuto, anelamento a $36{ }^{\circ} \mathrm{C}$ por 1 minuto e extensão a $72^{\circ} \mathrm{C}$ por 1 minuto, seguido de uma extensão final de 7 minutos a $72{ }^{\circ} \mathrm{C}$. Após a amplificação foi realizada eletroforese em gel de agarose a 1,6\% e, após ser corado por brometo de ethidium (20 minutos), o gel foi visualizado em aparelho de UV e fotodocumentado.

\section{Controles positivos e negativos}

Para controle de qualidade da técnica de PCR e RAPD-PCR, em todas as amplificaçóes foram empregadas amostras referências de L. braziliensis, L. amazonensis e L. infantum. Como controles negativos foram usados o mix, sem acréscimo de DNA e um mix com DNA extraído do sangue de cães oriundos de zona indene (nascidos em Curitiba e com sorologia negativa). Em todas as etapas também foram realizados controles de extração.

Para as técnicas sorológicas, foram empregados soros de dois animais comprovadamente positivos (procedentes de Belo Horizonte e com isolamento do parasito) e como controle negativo foram usados soros de dois animais vindos de zona indene (nascidos em Curitiba).

\section{Amostras referências}

As amostras referências usadas no presente trabalho, como controles positivos para as técnicas moleculares, seguiram as recomendaçóes da Organizaçáo Mundial da Saúde (WHO, 2001): Leishmania (L.) infantum (MHOM/FR/71/LRM75); Leishmania (V.) braziliensis (MHOM/BR/00/LTB300) e Leishmania (L.) amazonensis (MHOM/BR/73/M2269). Foram descongeladas, repicadas semanalmente e processadas como os isolados para as etapas de extração de DNA para a realização das técnicas de PCR e RAPD-PCR. As amostras foram doadas pelo Laboratório de Ecologia Médica (LEM) de Montpellier, França, e mantidas em nitrogênio líquido no Laboratório de Parasitologia Molecular da Universidade Federal do Paraná. A escolha das três espécies foi devida ao fato delas apresentarem maior distribuição geográfica no Brasil.

\section{Resultados e Discussão}

Nos 24 animais avaliados, os sinais clínicos mais frequentes foram: onicogrifose $(94,8 \%)$, linfadenomegalia $(82,8 \%)$, caquexia $(57,57 \%)$, alopecia $(65,45 \%)$, descamação furfurácea $(63,36 \%)$, 
úlceras $(40,2 \%)$ e palidez de mucosa oral e conjuntival. Um animal apresentou lesão de mucosa nasal. Esses sinais clínicos são compatíveis com LV canina (FEITOSA et al., 2000; ALMEIDA et al., 2005). $\mathrm{Na}$ classificação de acordo com os sinais clínicos, verificou-se que $62 \%$ dos cães eram polissintomáticos, $18 \%$ oligossintomáticos e $20 \%$ assintomáticos. Os dados observados são compatíveis com os achados clínicos apresentados por Gontijo e Melo (2004) e Brasil (2004). Vale ressaltar que, se um animal apresentou resultado positivo para Leishmania, todos os demais da mesma residência foram examinados e material colhido para exame, o que justifica o encontro de $20 \%$ de cães positivos e assintomáticos. Animais assintomáticos podem servir de fonte de infecção para os flebotomíneos e disseminação da doença, como já ressaltaram Alvar et al., 2004.

Observou-se que $40 \%$ dos animais apresentaram anemia com o número de eritrócitos variando de 4,20 a 4,76 milhóes por $\mathrm{mm}^{3}$. Em 50\% dos casos, a anemia era normocítica hipocrômica. Leucocitose associada à neutrofilia foram constatadas em 52\% dos casos, linfocitose em $65 \%$ e eosinofilia em $15,62 \%$. A concentração de proteína plasmática variou de 8,6 a 10,8 g.dL $\mathrm{dL}^{-1}$. Os níveis de AST e ALT apresentaram-se moderadamente alterados com $43,0 \pm 17,2$ e $25,5 \pm 3,2$ respectivamente. Uréia ficou dentro dos valores de referência em $68 \%$ dos casos. Autores como Albuquerque et al. (2007) observaram resultados semelhantes em cáes com sinais clínicos de LV. Dados destes exames, quando avaliados cuidadosamente, podem ser úteis para alertar os Clínicos Veterinários, de zona indene, a solicitarem exames específicos para confirmar ou não a leishmaniose visceral.

Noventa e dois por cento dos animais apresentaram sorologia positiva em ambas as técnicas usadas. Na RIFI, os títulos variaram de 1:40 a 1:2560. No teste de ELISA, as absorbâncias variaram de 0,139 a 1,640. Métodos sorológicos são excelentes para triagem em leishmaniose visceral. Todavia, o exame parasitológico é indispensável para a confirmação da espécie sob estudo. $\mathrm{O}$ cultivo de Leishmania foi positivo no material de 19 animais, os outros cinco cães tiveram diagnóstico confirmado para outras etiologias, como erlichiose, demodicose.

Para identificar os parasitos optou-se por métodos moleculares uma vez que vem sendo empregado por muitos autores (QUINNELL et al., 2001, LACHAUD et al., 2002, GOMES et al., 2007). A técnica de PCR permitiu amplificar fragmentos de $145 \mathrm{pb}$ em 14 isolados, o que caracteriza $L$. (L.) infantum (Figura 1). As cinco amostras que não apresentaram amplificação para o fragmento esperado foram submetidas à técnica de RAPD-PCR, e quatro (CUR338, CUR339, CUR342 e CUR350) apresentaram perfil eletroforético compatível com L.(V.) braziliensis (Figura 2), espécie autóctone no Estado do Paraná (THOMAZ-SOCCOL et al., 2003; CASTRO et al., 2007), embora os animais tivessem sinais clínicos similares aos de LV como descamação epitelial, magreza, onicogrifose, entre outros. A amostra CUR 291 apresentou perfil eletroforético diferente das amostras referências incluídas no presente estudo e dos demais isolados, provavelmente trata-se de outra espécie.

Todos os casos confirmados de LV foram avaliados epidemiologicamente com levantamento da procedência dos animais, tempo de residência e com pesquisa do vetor no local de residência. Verificou-se que os cães com LV eram procedentes de

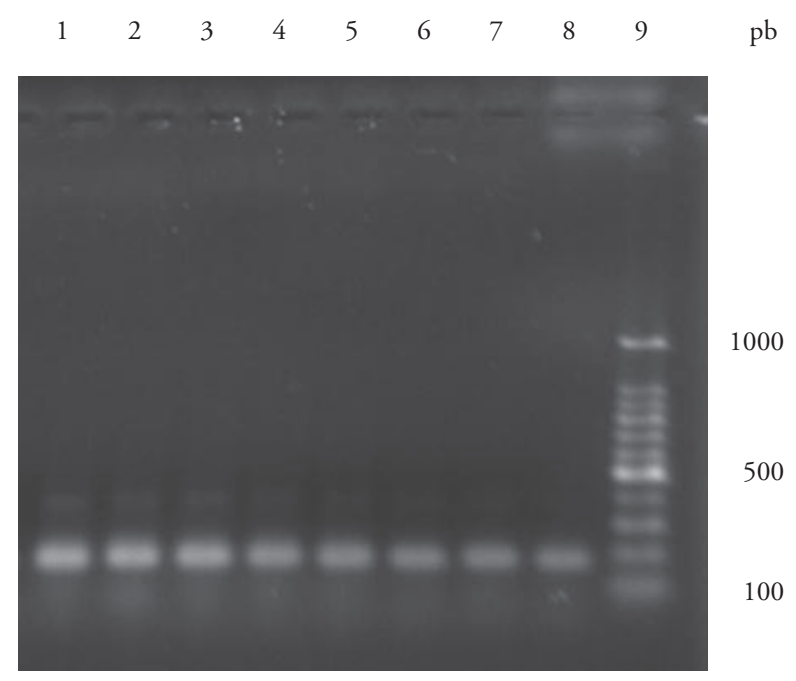

Figura 1. Perfil dos produtos de amplificação do DNA pela técnica de PCR dos isolados e amostra referência de $L$. (L.) infantum com os iniciadores RV1 e RV2. Eletroforese em gel de agarose 1,6\%. 1: CUR189; 2: CUR193; 3: CUR210; 4: CUR211; 5: CUR 240; 6: CUR268; 7: CUR269; 8: Amostra referência L. (L.) infantum; 9: Marcador Molecular $100 \mathrm{pb}$ (Invitrogen).

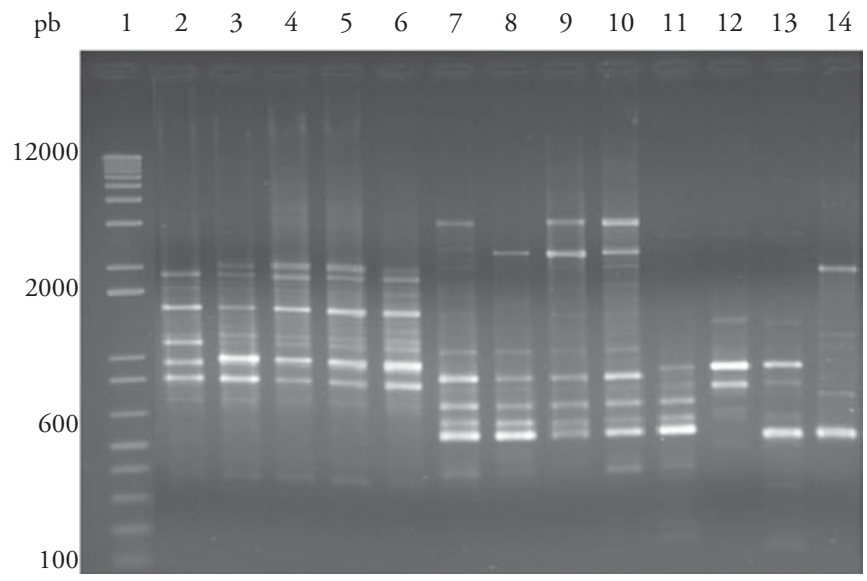

Figura 2. Perfil dos produtos de amplificação do DNA pela técnica de RAPD dos isolados de Leishmania em cães e amostras referências do protozoário com o iniciador A9. Eletroforese em gel de agarose 1,6\%. 1: Marcador Molecular $1 \mathrm{~Kb}$ (Invitrogen); 2: Amostra referência de L. braziliensis; 3: CUR338; 4: CUR342, 5: CUR350; 6: CUR339; 7: CUR 189; 8: CUR210; 9: CUR269; 10: CUR268; 11: CUR240; 12: CUR291; 13: Amostra referência L. infantum; 14: Amostra referência $L$. amazonensis.

áreas diferentes, mas endêmicas (Tabela 1), e adoeceram em zona indene, sendo, portanto, casos alóctones. Muitos animais estavam em tratamento para sarna ou doenças hormonais há mais de um ano, retardando o diagnóstico correto. $\mathrm{O}$ encontro de animais positivos para LV em zona indene, como na Região Sul, deve ter o diagnóstico confirmado por isolamento do parasito, e sua correta identificação feita por laboratórios de reconhecida competência. 
Tabela 1. Dados dos cães segundo a procedência e o resultado dos exames laboratoriais para Leishmania sp.

\begin{tabular}{|c|c|c|c|c|c|}
\hline \multirow{2}{*}{ Código } & \multirow{2}{*}{ Local de origem / local de notificaçáo } & \multicolumn{4}{|c|}{ Exames realizados } \\
\hline & & IFI Título $\geq 1: 40$ & ELISA D.O. $\geq 0,135$ & PCR & RAPD \\
\hline 189 & Belo Horizonte - MG / Curitiba & + & + & $L . i$ & $L . i$ \\
\hline 210 & Belo Horizonte - MG / Curitiba & + & + & $L . i$ & $L . i$ \\
\hline 211 & Belo Horizonte - MG / Curitiba & + & + & $L . i$ & $L . i$ \\
\hline 269 & Belo Horizonte - MG / Londrina & + & + & $L . i$ & $L . i$ \\
\hline 291 & Desconhecida / Curitiba & + & + & - & $L . b$ \\
\hline 338 & Arapongas & + & + & - & $L . b$ \\
\hline 339 & Arapongas & + & + & - & $L . b$ \\
\hline 350 & Arapongas & + & + & - & $L . b$ \\
\hline 362 & Aracaju - SE / Curitiba & + & + & L.i & L.i \\
\hline 363 & Três Coraçōes - MG / Curitiba & + & + & $L . i$ & $L . i$ \\
\hline 372 & Três Lagoas - MS / Curitiba & + & + & $L . i$ & $L . i$ \\
\hline 376 & Campo Grande - MS / Curitiba & + & + & $L . i$ & $L . i$ \\
\hline 383 & Tocantins / Santa Catarina / Curitiba & + & + & L.i & L.i \\
\hline Susi & Belo Horizonte - MG / Curitiba & - & - & - & - \\
\hline Daiane & Belo Horizonte - MG / Curitiba & - & - & - & - \\
\hline July & Belo Horizonte - MG / Curitiba & - & - & - & - \\
\hline Stephany & Belo Horizonte - MG / Curitiba & - & - & - & - \\
\hline
\end{tabular}

$L . i=$ Leishmania $(L$.$) infantum; L . b=L .($ V.) braziliensis.

Ainda é imprescindível que seja avaliada, junto com as autoridades de Saúde Pública, a autoctonia dos casos e que sejam tomadas medidas de vigilância e controle de LV, conforme recomendaçóes do Ministério da Saúde. Pelo fato da leishmaniose visceral ser uma zoonose e ter o cão doméstico como o principal reservatório, os casos diagnosticados devem ter avaliação epidemiológica e vetorial, pois a migração desses animais pode disseminar a doença para outras regióes, desde que encontrem ecótopo adequado e vetor específico.

A participação das clínicas veterinárias como sentinelas no monitoramento da LV canina, em zona indene, deverá ser buscada e, mediante campanhas de conscientização, mobilizar os profissionais ligados à saúde e as populaçôes locais em torno de uma ampla discussão sobre o impacto dessa zoonose na Saúde Pública (JULIÃO et al., 2007). Seria fundamental ainda que o Ministério da Agricultura (MAPA) exigisse exames sorológicos negativos para permitir a entrada de animais de zona endêmica para zona indene, antes de autorizar guia de trânsito.

\section{Agradecimentos}

Este trabalho teve financiamento de UGF/SETI, Fundação Araucária e CNPq.

\section{Referências}

ABRANCHES, P. et al. Canine leishmaniosis: pathological and ecological factors influencing transmission of infection. The Journal of Parasitology, v. 77, n. 4, p. 557-561, 1991.

ALBUQUERQUE, A. L. et al. Aspectos clínicos de cães naturalmente infectados por Leishmania (Leishmania) chagasi na região metropolitana do Recife. Clinica Veterinária, v. 71, n. 1, p. 78-80, 2007.

ALMEIDA, M. A. et al. Antileishmanial antibody profile in dogs naturally infected with Leishmania chagasi. Veterinary Immunology and Immunopathology, v. 106, n. 1-2, p. 151-158, 2005.

ALVAR, J. et al. Canine leishmaniasis. Advances in Parasitology, v. 57 , n. 3, p. 1-88, 2004.

BAÑULS, A. L. Apport de la genetique evolutive a l'epidemiologie et a la taxonomie du genre Leishmania. Montpellier, França, 1998. 196 f. Tese (Doutorado) - Université Montpellier II.

BORASCHI, C. S. S.; NUNES, C. M. Aspectos epidemiológicos da leishmaniose visceral urbana no Brasil. Clinica Veterinária, v. 71, n. 1, p. 44-48, 2007.

BRASIL. Ministério da Saúde. Secretária de Vigilância em Saúde. Disponível em:<http://portal.saude.gov.br/portal/saude/visualizar_texto. cfm?idtxt $=25340>$. Acesso em: 008. 
BRASIL. Ministério da Saúde, Secretaria de Vigilância em Saúde. Nota técnica sobre vacina antileishmaniose visceral canina. Brasília, 2004.

CASTRO, E. A.; THOMAZ-SOCCOL, V.; AUGUR, C. Standardization of ELISA (Enzyme linked immunosorbent Assay) and Indirect Fluorescent Antibody Test (IFAT) techniques for canine cutaneous leishmaniasis. In: ROUSSOS, S. et al. (Eds.). New Horizons in Biotechnology. [S.l.]: Kluwer Academic Publishers, 2003. p. 421-428,

CASTRO, E. A. et al. Leishmania (Viannia) braziliensis: Epidemiology of canine leishmaniasis in the State of Paraná (Brazil). Experimental Parasitology, v. 117, n. 1, p. 13-21, 2007.

BONI, M. ; DAVOUST, B. ; DEREURE, J. Intérêt des techniques de laboratoire dans le diagnostic de la leishmaniose canine. Revue Française des Laboratoires, v. 1999, n. 310, p. 33-38, 1999.

FEITOSA, M. M. et al. Aspectos Clínicos de Cães com Leishmaniose Visceral no Município de Araçatuba - São Paulo. Clinica Veterinária, v. 28 , n. 1 , p. $36-44,2000$.

GARCIA-NAVARRO, C. E.; PACHALY, J. R. Manual de Hematologia Veterinária. São Paulo: Livraria e Editora Varela, 1994.

GOMES, A. H. S. et al. PCR identification of Leishmania in diagnosis and control of canine leishmaniasis. Veterinary Parasitology, v. 144, n. 3-4, p. 234-241, 2007.

GONTIJO, C. M. F.; MELO, M. N. Leishmaniose Visceral no Brasil. Revista Brasileira de Epidemiologia, v. 7, n. 3, p. 338-349, 2004.

JULIÂO, F. S. et al. Investigação de áreas de risco como metodologia complementar ao controle da leishmaniose visceral canina. Pesquisa Veterinária Brasileira, v. 27, n. 8, p. 319-324, 2007.

KOCH, R. Die Aetiologie der Tuberculose. Berl. Klin. Wchuschr, v. XIX, n. 2, p. 221-230, 1882.

LACHAUD, L. et al. Comparison of various sample preparation methods for PCR diagnosis of visceral leishmaniasis using peripheral blood. Journal Clinical Microbiology, v. 39, n. 1, p. 613-617, 2002.

LAINSON, R.; SHAW, J. J. Evolution, classification and geographical distribution. In: PETERS, W.; KILLICK-KENDRICH, R. (Eds). The Leishmaniases in Biology and Medicine. [S.1.]: Academic Press, 1987. p. 1-120.

MOLINA, R. et al. Infectivity of dogs naturally infected with Leishmania infantum to colonized Phlebotomus perniciosus. Transaction of Royal Society of Tropical Medicine and Hygiene, v. 88, n. 4, p. 491-493, 1994.
MORENO, G. et al. Le complexe Leishmania donovani s.l. Analyse enzymatique et traitment numérique. Individualisation du complexe Leishmania infantum. Corollaires biogéographiques et phylétiques. A propos de 146 souches originaires de l'Ancien et du Nouveau Monde. In : COLLOQUE INTERNATIONAL CNRS/INSERM, 1984. Leishmania. Taxonomie et Phylogenése. Applications éco-épidémiologiques. Montpellier : IMEEE, 1986. p. 105-117.

QUINNELL, R. J. et al. Detection of Leishmania infantum by PCR, serology and cellular immune response in a cohort study of Brazilian dogs. Parasitology, v. 122, n. 3, p. 253- 261, 2001.

PEREIRA, E. F. A. Viabilidade genética e diagnóstico molecular da Leishmania spp., pelas técnicas de RAPD e PCR, no estado do Paraná e casos importados- Brasil. Curitiba, 2005. 65 f. Dissertação (Mestrado em Microbiologia, Parasitologia e Patologia) - Universidade Federal do Paraná.

PEREIRA, E. F. A. et al. Molecular diagnosis of leishmaniosis in the Paraná state of southern Brazil. Experimental Dermatology, v. 17, n. 12, p. 1024-1030, 2008.

RIOUX, J. A. Recommendations. In: Leishmania. Taxonomy and phylogeny. Applications to ecology and epidemiology. RIOUX, J. A. (Ed.). [S.1.]: IMEEE, 1986. p. 513-517.

SILVA, E. S. et al. Visceral Leishmaniasis in the Metropolitan Region of Belo Horizonte, State of Minas Gerais, Brazil. Memórias do Instituto Oswaldo Cruz, v. 3, n. 3, p. 285-291, 2001.

THOMAZ-SOCCOL, V. Les Leishmania du Noveau Monde. Analyse enzymatique. Demarche progressive phenetique-cladistique. 1993. 190 p. Tese (Doutorado em Parasitologia) - Université Montpellier I.

THOMAZ-SOCCOL, V. et al. Phylogenetic taxonomy of New World Leishmania. Annales de Parasitologie Humaine et Comparée, v. 68, n. 1, p. 104-106, 1993.

THOMAZ-SOCCOL, V. et al. Leishmania species in two regions of Paraná, Brazil: bioquemical caracterization by isoenzyme electrophoresis. In: ROUSSOS, S. et al. (Eds). New Horizons in Biotechnology. Dordrecht: Kluwer Academic Publishers, 2003. p. 429-439.

World Health Organization - WHO. Control of the leishmaniases. Geneva, 1990. 158 p. (Technical Report Series).

World Health Organization - WHO. The world health report. Geneva, 2001. 